\title{
PEMANFAATAN PENGEMBANGAN JARINGAN GAS BUMI SEBAGAI PENGGANTI LPG RUMAH TANGGA DI KABUPATEN BOJONEGORO- JAWA TIMUR
}

\section{Utilization of natural gas network development for household LPG replacement in Bojonegoro Regency-East Java}

\author{
Andriawan1, Rahmat Budiman' dan Dwijaya Febriansyah²* \\ 1PT. Pertamina Gas, Jl. M.H Thamrin Kav. 55 Jakarta Pusat 10350, Indonesia \\ ${ }^{2}$ Badan Pengkajian dan Penerapan Teknologi, Jl. M.H Thamrin No. 8 Jakarta Pusat 10340, Indonesia
}

Informasi artikel

Diterima: $26 / 12 / 2019$ Direvisi : 10/01/2020 Disetujui: 20/01/2020

\begin{abstract}
Abstrak
Kajian ini dilakukan untuk mengetahui penghematan biaya yang diperoleh responden rumah tangga dari pemanfaatan pengembangan jaringan gas bumi (jargas) yang akan dipasang untuk menggantikan LPG di 7 kelurahan, kecamatan Bojonegoro, kabupaten Bojonegoro, Jawa Timur. Dari 4,000 responden yang setuju rumahnya dipasang jargas, seluruhnya masih menggunakan Liquefied Petroleum Gas (LPG) sebagai bahan bakar dirumahnya. Sebagian besar responden (93\%) diketahui memakai LPG 3 kg (subsidi), 6\% LPG 12 kg dan 1\% LPG 5.5 $\mathrm{kg}$ untuk kebutuhan rumah tangga mereka. Secara komersial, penghematan biaya yang didapat dari pemanfaatan pengembangan jaringan gas bumi terhadap pemakaian LPG $3 \mathrm{~kg}$ yaitu Rp 878, /tabung, LPG $5.5 \mathrm{~kg}$ : Rp 71,277,-/tabung dan LPG $12 \mathrm{~kg}$ : Rp 76,913,/tabung. Jumlah kebutuhan gas bumi rata-rata setiap rumah/responden adalah $12,39 \mathrm{~m} 3 /$ bulan. Total kebutuhan gas untuk pemakaian jargas 4,000 responden rumah tangga adalah sebesar 0.062 mmscfd dan untuk seluruh rumah tangga di kabupaten Bojonegoro adalah sebesar $6.48 \mathrm{mmscfd}$.
\end{abstract}

Kata Kunci: gas bumi, jargas, LPG, penghematan biaya, Bojonegoro.

\begin{abstract}
This study was purposed to determine the cost saving obtained by household respondents from utilization of natural gas network development which will be installed replacing LPG uses in Bojonegoro regency. All 4,000 respondents still using Liquified Petroleum Gas (LPG) as fuel. Most of the respondents (93\%) using LPG $3 \mathrm{~kg}$ (subsidy), 6\% LPG $12 \mathrm{~kg}$ and 1\% LPG $5.5 \mathrm{~kg}$ for their household needs. Commercially, cost savings obtained from natural gas network development instead LPG $3 \mathrm{~kg}$ is Rp 878,-/bottle, LPG $5.5 \mathrm{~kg} R \mathrm{Rp}$

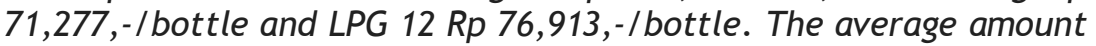
of natural gas per house is $12.39 \mathrm{m3} / \mathrm{month}$. Total gas demand for 4,000 household respondents is $0.062 \mathrm{mmscfd}$ and for all households in Bojonegoro regency is $6.48 \mathrm{mmscfd}$.
\end{abstract}

Keywords: natural gas, gas network, LPG, cost saving, Bojonegoro.

*Penulis Korespondensi. Handphone: 081286098764

email : dwi.jaya@bppt.go.id 


\section{PENDAHULUAN}

Gas bumi adalah komoditas energi tak terbarukan yang berperan penting dalam memenuhi kebutuhan energi primer di dunia. Pada tahun 2017, tercatat kebutuhan gas bumi di seluruh dunia mencapai $23.4 \%$ dari total kebutuhan energi primer global (Marques dan Silva, 2019). Gas bumi merupakan salah satu energi yang dibutuhkan bagi setiap negara, dimana dalam proses pembangunan sebuah negara, dibutuhkan sejumlah energi yang setiap tahunnya akan berkembang semakin banyak. Gas bumi memiliki peran yang sangat penting sebagai energi primer ketiga yang paling banyak digunakan di dalam negeri setelah minyak bumi dan batu bara, dalam mendukung kehidupan masyarakat dan menggerakkan perekonomian Indonesia. Dalam kehidupan sehari-hari, gas bumi dipakai sebagai bahan bakar untuk memasak, pemanas air, mengelas, menggerakkan turbin dan generator untuk menghasilkan pupuk dan listrik, bahan bakar gas untuk transportasi (BBG), bahan baku petrokimia, peleburan baja, industri kaca, keramik, aditif dan lain sebagainya (Neraca Gas Bumi Indonesia 20182027, 2018).

Pembangunan jaringan distribusi gas bumi (jargas) untuk rumah tangga merupakan upaya pemerintah dalam mewujudkan ketahanan energi serta meningkatkan kesejahteraan masyarakat. Jargas adalah jaringan pipa distribusi yang dibangun dan dioperasikan untuk penyediaan dan pendistribusian gas bumi untuk rumah tangga dan pelanggan kecil. Jargas biasanya dibangun di daerah yang dekat dengan sumber gas atau infrastruktur pipa gas, memiliki spesifikasi gas yang terpenuhi, adanya potensi pasar pengguna jargas, komitmen pemerintah daerah dan memenuhi kaidah keselamatan dan keteknikan (Peraturan Presiden Republik Indonesia Nomor 6 tahun 2019).

Secara umum, jargas dibangun dengan melakukan tapping di sumber gas, kemudian gas mengalir menuju Metering \& Regulating System (MRS) untuk diturunkan tekanannya menjadi tekanan menengah ( 1 - 4 barG) dan diukur volumenya. Odoran (pembau) ditambahkan setelah MRS, untuk mengetahui adanya kebocoran gas dalam jaringan. Selanjutnya gas dialirkan melalui pipa tekanan menengah ke Regulating Station (RS) untuk diturunkan tekanannya menjadi tekanan rendah (100 - 350 mbarG) dan didistribusikan melalui jaringan pipa bertekanan rendah. Dari jaringan bertekanan rendah inilah gas dialirkan ke pelanggan rumah tangga melalui regulator dan meter gas. Gas yang sampai di pelanggan rumah tangga bertekanan maksimum 20-23 mbarG (KESDM, 2016). Adapun total sambungan rumah yang terpasang di Indonesia sampai akhir 2018 yaitu 325,773 sambungan di 40 kabupaten/kota dengan pemakaian 10-15 $\mathrm{m} 3$ /bulan (KESDM, 2019).

Kabupaten Bojonegoro merupakan salah satu wilayah penghasil minyak dan gas bumi terbesar di Jawa Timur, dengan jumlah rumah tangga sebesar 415,733 rumah tangga (Kabupaten Bojonegoro Dalam Angka. Seksi Inte, 2019). Eksplorasi dan eksploitasi migas di Kabupaten Bojonegoro telah dilakukan di seluruh kawasan. Cadangan pasti minyak Indonesia yang berada di wilayah ini diperkirakan sekitar 25 persen dari cadangan nasional. Setidaknya terdapat 4 (empat) blok dan beberapa lapangan migas, yaitu : 1). Blok Cepu Lapangan Banyu Urip dan Lapangan Kedung Keris yang dikelola ExxonMobil melalui anak perusahaan ExxonMobil Cepu Ltd dengan produksi $\pm 229,000$ BOPD, Lapangan Kawengan yang dikelola oleh Pertamina Field Cepu Asset IV dengan produksi $\pm 1,239$ BOPD; 2). Blok Tuban Lapangan Sukowati yang dikelola oleh Pertamina Asset IV dengan produksi $\pm 9,842$ BPOD; 3). Blok Cepu Lapangan JambaranTiung Biru, dimana masih dalam tahap konstruksi dengan perkiraan produksi gas tahun 2021 yaitu \pm 192 MMSCFD; 4). Blok Blora dimana wilayah kerjanya meliputi kecamatan Ngraho dan Margomulyo Kabupaten Bojonegoro, serta Blok Nona yang wilayah kerjanya meliputi wilayah Bojonegoro Bagian Tenggara (Timur-Selatan), dimana kedua blok tersebut baru tahap eksplorasi (Migas Bojonegoro, 2019).

Berdasarkan data cadangan migas dan jumlah rumah tangga, Kabupaten Bojonegoro memiliki potensi untuk dilakukan pengembangan dan pemanfaatan jaringan gas bumi sebagai pengganti LPG untuk keperluan sehari-hari. Beberapa studi tentang pengembangan dan pemanfaatan jaringan gas bumi telah dilakukan sebelumnya. Valentino, (Valentino, 2012) meneliti pengembangan jaringan distribusi gas bumi di kota Depok, Jawa Barat dengan simulasi piranti lunak sistem perpipaan. Wiguna dkk, (Wiguna et al., 2015) membuat model spasial untuk mengetahui pola pelayanan gas dan menemukan lokasi optimal potensi pengguna jaringan gas di kabupaten 
Bekasi, Jawa Barat. Lestari \& Aliasuddin, (Lestari dan Aliasuddin, 2016) mensurvei 100 rumah tangga untuk mengetahui kesediaan masyarakat dalam membayar (willingness to pay) terhadap jaringan gas bumi di kota Lhokseumawe, Aceh. Triyatno, (Tiyanto, 2018) mensurvei 118 pengguna LPG di Bontang, Kalimantan Timur untuk mengetahui perbandingan penggunaan gas alam terhadap LPG untuk kebutuhan seharihari. Copiello, (Capielo, 2018) mengkaji potensi konsumsi gas alam dan kelayakan ekonomi jaringan gas di pulau Sardinia, Italia. Liu dkk, (Liu et al., 2018) menginvestigasi konsumsi gas alam per kapita di 30 provinsi di China untuk memprediksi skenario yang mungkin dilakukan pemerintah untuk meningkatkan dan mengoptimalkan rencana pengembangan gas bumi selanjutnya. Yulianita, (Yulianti, 2019) meneliti persepsi masyarakat di salah satu wilayah di kota Bandar Lampung terhadap pembangunan jaringan gas rumah tangga dengan metode deskriptif kuantitatif.

Dalam studi ini akan dijelaskan potensi pengembangan dan pemanfaatan jaringan distribusi gas bumi di kabupaten Bojonegoro. Studi ini bertujuan untuk memprediksi jumlah pemakaian jaringan gas bumi berdasarkan pemakaian LPG dan mengetahui perbandingan biaya yang dikeluarkan ketika menggunakan gas bumi dan LPG pada skala rumah tangga di kabupaten Bojonegoro.

\section{METODOLOGI}

Penelitian ini menggunakan metode survei minat kepada 4,000 responden yang setuju rumahnya dipasang jaringan gas bumi di kecamatan Bojonegoro Kota yang meliputi 7 kelurahan yaitu Kadipaten, Kepatihan, Klangon, Mojo Kampung, Ngrowo, Sukorejo dan Sumbang. Peta target wilayah calon pelanggan gas bumi di kabupaten Bojonegoro ditunjukkan pada Gambar 1.

Kriteria responden adalah rumah tinggal sendiri bukan rumah sewa, rumah tidak digunakan untuk kegiatan komersial, bangunan permanen, warga tetap wilayah tersebut dan menggunakan LPG atau minyak tanah dalam kegiatan memasak. Proses survei minat yang dilakukan terhadap responden ditunjukkan pada Gambar 2.

Sebelum survei minat dilakukan terlebih dahulu dilakukan koordinasi dan pengurusan perijinan ke pemerintah kabupaten Bojonegoro. Perijinan pengembangan jaringan distribusi gas bumi meliputi ijin usaha, galian jalan, lingkungan, crossing jalan nasional, crossing sungai besar, crossing rel kereta api, dan tie in.

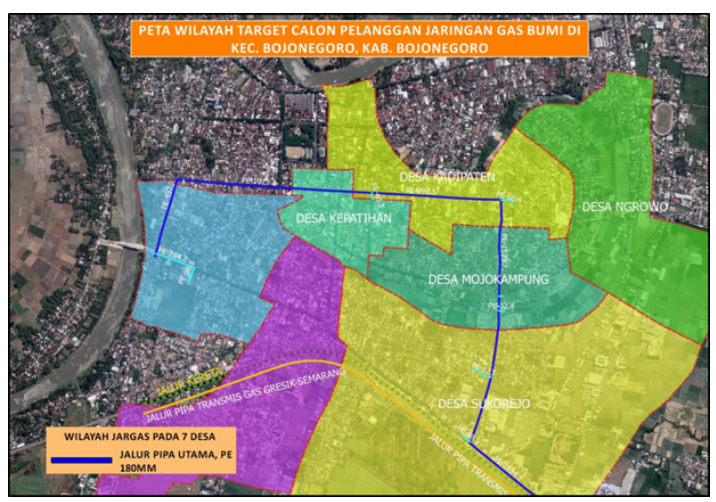

Gambar 1 Target wilayah calon pelanggan gas bumi di kabupaten Bojonegoro (PT. Pertamina Training \& Consulting, 2018)

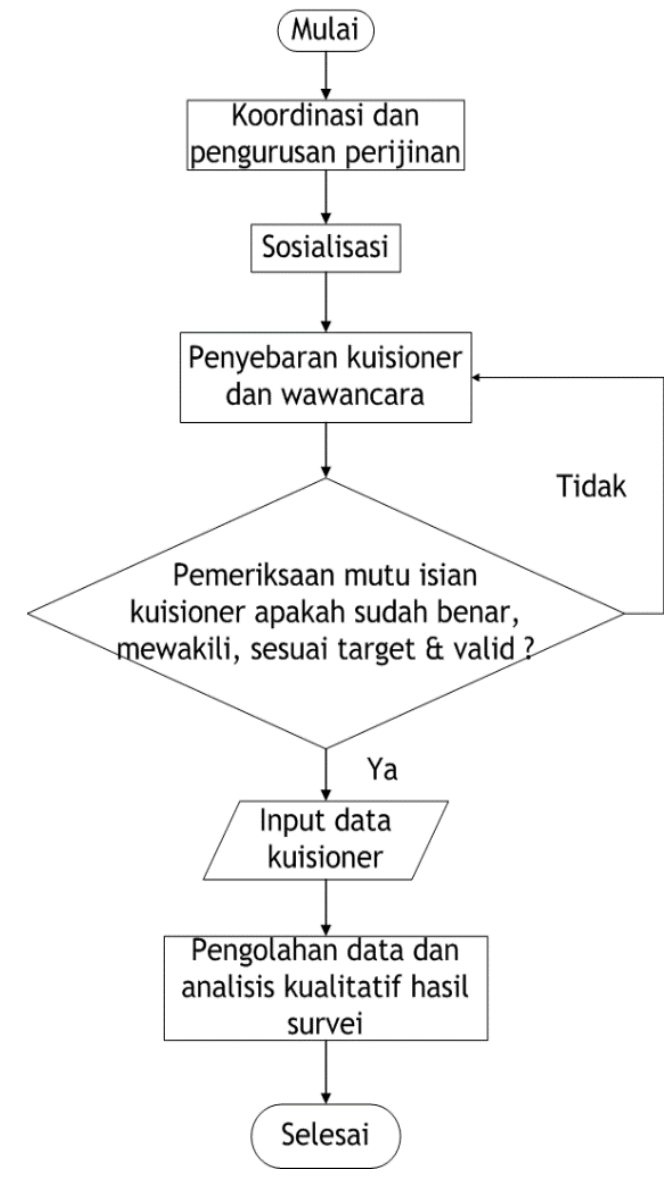

Gambar 2 Diagram alir survei minat

Selanjutnya sosialisasi survei minat dilakukan mulai tingkat kecamatan, kelurahan dan RW (Rukun Warga) seperti yang ditunjukkan pada Gambar 3.

Materi sosialisasi yang disampaikan adalah informasi wilayah kelurahan penerima jargas, penjelasan singkat mengenai keselamatan jaringan gas dan rencana pelaksanaan survey calon pelanggan. 


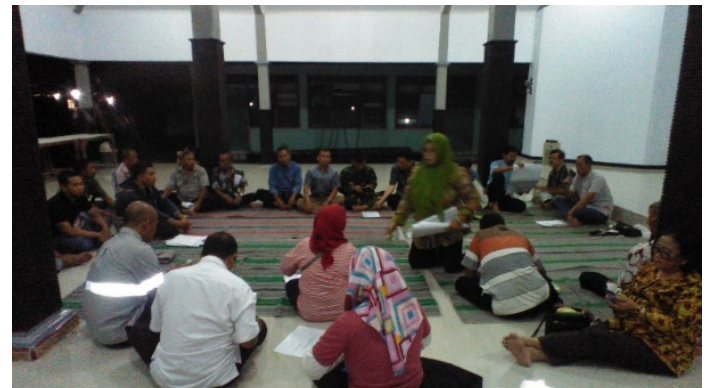

Gambar 3 Pelaksanaan sosialisasi (PT. Pertamina Training \& Consulting, 2018)

Survei minat dilakukan ke setiap rumah yang telah ditentukan dengan menyebar kuisioner dan wawancara pengisian kuisioner. Setelah penyebaran kuisioner dilakukan, perlu dilakukan pemeriksaan mutu terhadap isian kuisionernya apakah sudah benar, mewakili, sesuai target dan valid. Jika belum maka perlu diulangi kembali penyebaran kuisionernya dan jika sudah maka data isian kuisioner dapat diinput kedalam database untuk diolah dan dianalisis. Dari hasil pengolahan data dan analisis kualitatif akan diperoleh jumlah pemakaian LPG rata-rata untuk setiap jenis tabung baik yang $3 \mathrm{~kg}, 5.5 \mathrm{~kg}$ dan $12 \mathrm{~kg}$. Setiap calon pelanggan atau responden yang telah disurvei dan diverifikasi datanya kemudian didokumentasikan seperti Gambar 4.

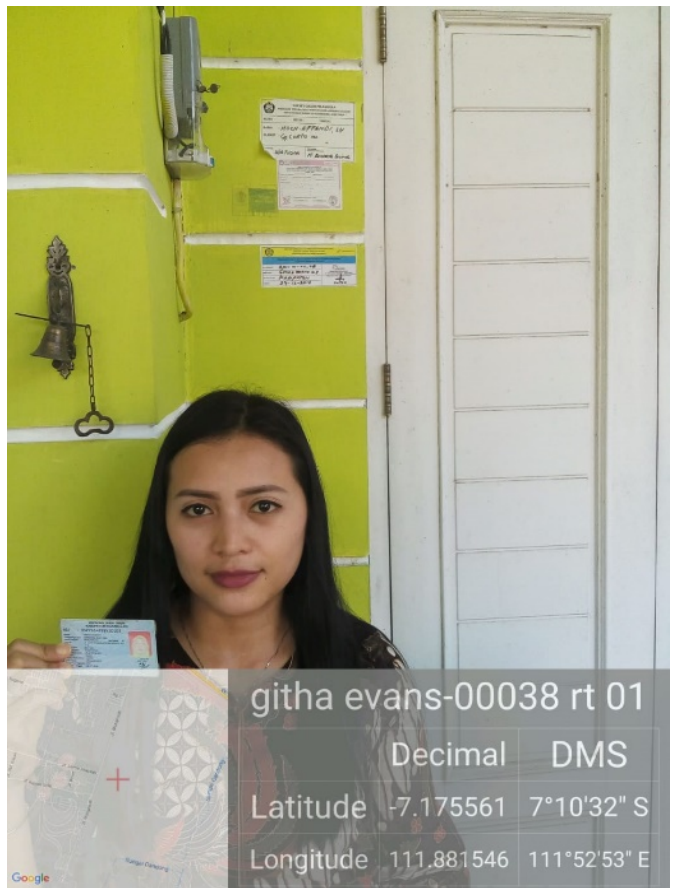

Gambar 4 Dokumentasi responden survei (PT. Pertamina Training \& Consulting, 2018)
Untuk mengetahui perkiraan jumlah pemakaian gas bumi dan biaya yang dikeluarkan ketika menggunakan gas bumi terlebih dahulu jumlah pemakaian LPG dikalikan dengan nilai bakarnya 11,255 $\mathrm{kkal} / \mathrm{kg}$ (Syukur, 2011) kemudian dikalikan dengan faktor konversi sehingga diperoleh jumlah pemakaian gas bumi setara LPG seperti pada persamaan berikut.

$$
\begin{gathered}
\text { Volume gas bumi }\left[\mathrm{m}^{3}\right]= \\
\frac{\left(1 \mathrm{~kg} \text { LPG } \times 11,255 \frac{\mathrm{kkal}}{\mathrm{kg}} \times 3.96567 \frac{\mathrm{btu}}{\mathrm{kkal}} \times 0.0265 \frac{\mathrm{m} 3}{\mathrm{scf}}\right)}{1.050 \frac{\mathrm{btu}}{\mathrm{scf}}}
\end{gathered}
$$

Selanjutnya jumlah gas bumi setara LPG dihitung volume dan biayanya untuk setiap jenis tabung LPG kemudian dibandingkan biayanya yang harus dikeluarkan oleh masyarakat kabupaten Bojonegoro. Selain itu total jumlah pemakaian gas bumi juga dihitung sesuai dengan jumlah responden dan jumlah total penduduk kabupaten Bojonegoro untuk memprediksi jumlah gas bumi yang harus didistribusikan.

\section{HASIL DAN PEMBAHASAN}

Setelah selama 10 tahun lebih konversi minyak tanah ke LPG dilakukan, 4,000 responden yang disurvey semuanya telah menggunakan LPG di rumahnya dan bersedia dipasang jaringan gas bumi sebagai bahan bakar untuk menggantikan LPG. Jumlah penggunaan LPG didominasi oleh pengguna LPG 3 kg sebanyak 3,471 orang (93\%), disusul LPG $12 \mathrm{~kg}$ sebanyak 229 orang (6\%) dan LPG $5.5 \mathrm{~kg}$ sebanyak 30 orang (1\%) seperti yang ditunjukkan pada Gambar 5.

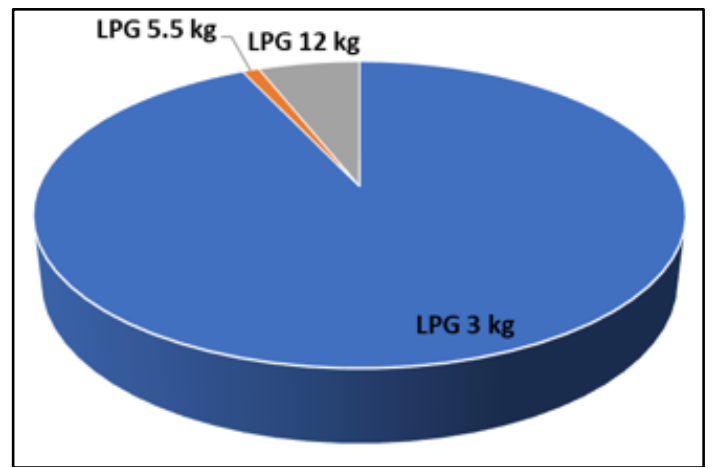

Gambar 5 Persentase penggunaan LPG tabung

LPG $3 \mathrm{~kg}$ merupakan jenis LPG tabung yang disubsidi Pemerintah, oleh karena itu sangat diminati dibandingkan dengan LPG 12 $\mathrm{kg}$. Adapun harga eceran tertinggi (HET) di Jawa Timur untuk LPG 3 kg yaitu Rp 16,000,- 
(Cahyono, 2019) dan HET LPG $12 \mathrm{~kg}$ yaitu Rp 137,400,- (No-Authors, 2017). Untuk LPG 5.5 kg yaitu Rp 99,000 tetap diminati dengan alasan lebih aman dan terjamin isinya (NoAuthors, 2016). Sedangkan untuk harga gas bumi sesuai keputusan BPH Migas yaitu Rp 4.250,- per m3 (Pratiwi and Yolanda, 2019). Hasil survey jajak minat jargas terhadap responden rumah tangga yang berada di kabupaten Bojonegoro ditunjukkan pada Tabel 1.

Tabel 1 Hasil survey jajak minat jargas di Kabupaten Bojonegoro

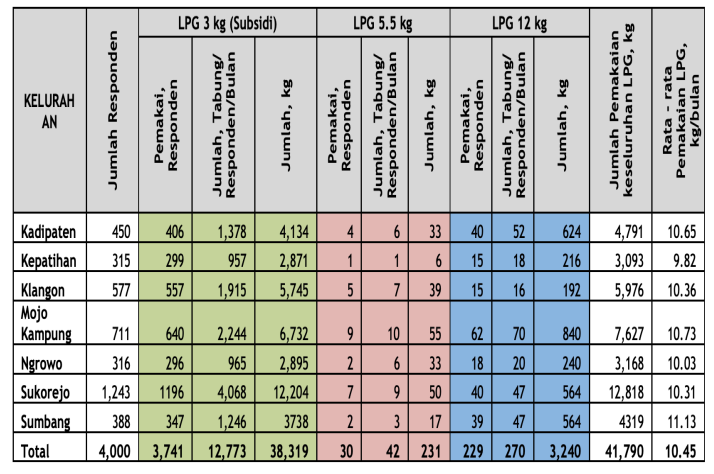

Tabel 1 menjelaskan hasil survey terhadap 4,000 responden yang tersebar di 7 Kelurahan di kabupaten Bojonegoro. Jumlah total responden yang memakai LPG $3 \mathrm{~kg}$ adalah 3,741 responden, LPG $5.5 \mathrm{~kg} 30$ responden, dan LPG $12 \mathrm{~kg} 229$ responden. Dari pemakaian 3 jenis tabung LPG setiap bulannya, jumlah total pemakaian LPG $3 \mathrm{~kg}$ sebesar $38,319 \mathrm{~kg}$, LPG $5.5 \mathrm{~kg}$ sebesar $231 \mathrm{~kg}$ dan LPG $12 \mathrm{~kg}$ sebesar $3,240 \mathrm{~kg}$ sehingga jumlah total pemakaian LPG oleh responden sebesar $41,790 \mathrm{~kg} /$ bulan. Total pemakaian LPG rata-rata setiap responden sebesar 10.45 $\mathrm{kg} /$ bulan.

Jumlah gas bumi dalam satuan meter kubik yang setara dengan $1 \mathrm{~kg}$ LPG adalah sebagai berikut:

Volume gas bumi $=\frac{\left(1 \mathrm{~kg} \mathrm{LPG} \times 11255 \frac{\mathrm{kkal}}{\mathrm{kg}} \times 3.96567 \frac{\mathrm{btu}}{\mathrm{kkal}} \times 0.0265 \frac{\mathrm{m} 3}{\mathrm{scf}}\right)}{1.050 \frac{\mathrm{btu}}{\mathrm{scf}}}=1.19\left[\mathrm{~m}^{3}\right]$

Hasil perhitungan jumlah gas bumi setara LPG untuk setiap jenis tabung dan perbandingan biayanya ditunjukkan pada Tabel 2. Volume gas bumi dihitung setara jumlah LPG pada masing-masing jenis tabung. Kemudian diperoleh harga gas bumi yang setara dengan masing-masing jenis tabung LPG. Dengan membandingkan harga gas bumi setara LPG dengan harga eceran tertinggi LPG maka diperoleh selisih harga yang merupakan jumlah penghematan yang akan diterima oleh responden apabila beralih ke gas bumi. Harga satuan gas bumi yang digunakan pada Tabel 2 adalah Rp 4,250,$/ \mathrm{m}^{3}$.

Tabel 2 Jumlah pemakaian gas bumi setara LPG dan perbandingan biayanya

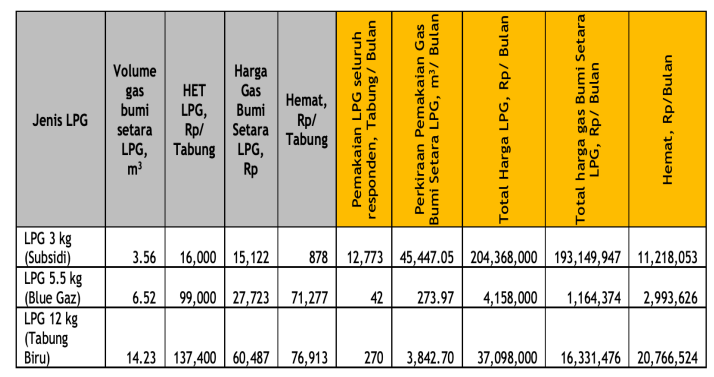

Dari Tabel 2 dapat dilihat bahwa dari sisi komersial pengguna, penghematan dari penggunaan jaringan gas bumi terhadap LPG $3 \mathrm{~kg}$ (subsidi) tidak signifikan di Bojonegoro (Rp 878,-/tabung) karena 93\% warga Bojonegoro memakai gas $3 \mathrm{~kg}$ yang di subsidi oleh pemerintah. Untuk LPG 5.5 dan $12 \mathrm{~kg}$ sangat signifikan $(>100 \%)$ karena penghematannya mencapai Rp 71,277,- (LPG $5.5 \mathrm{~kg}$ ) dan Rp 76,913,- (LPG $12 \mathrm{~kg}$ ).

Berdasarkan jumlah rata-rata pemakaian LPG setiap rumah/responden dan volume gas bumi setara LPG, maka jumlah kebutuhan gas bumi rata-rata setiap rumah/responden adalah $12.39 \mathrm{~m} 3 /$ bulan sedangkan kebutuhan gas bumi untuk 4,000 responden rumah tangga (kepala keluarga) yaitu sebesar 49,564 $\mathrm{m} 3 /$ bulan atau 1.87 mmscf/ bulan atau 0.062 mmscfd.

Nilai penghematan yang akan diterima oleh masyarakat Bojonegoro apabila beralih dari LPG ke gas bumi lebih signifikan atau terasa bagi pengguna LPG $5.5 \mathrm{~kg}$ dan $12 \mathrm{~kg}$ karena mereka cukup membayar 28\% dari HET LPG $5.5 \mathrm{~kg}$ dan 44\% dari HET LPG $12 \mathrm{~kg}$. Penghematan dari penggunaan jaringan gas bumi terhadap LPG $3 \mathrm{~kg}$ (subsidi) tidak signifikan di Bojonegoro (Rp 878,-/tabung) karena 93\% warga Bojonegoro memakai gas 3 kg yang di subsidi oleh pemerintah, tetapi jika dilihat dari keuntungan yang lain jaringan gas tetap lebih unggul yaitu : praktis, tidak khawatir gas habis ditengah pemakaian dan cukup merepotkan untuk membelinya ke agen atau warung. Selain itu jaringan pipa gas bumi sangat aman karena tekanan jaringan gas bumi yang sampai ke rumah sangat rendah maksimum 20-23 mbarG (KESDM, 2016) dibandingkan LPG (12 barG), selain itu persediaan gas bumi melimpah selama jaringan gas tersambung ke produsen gas bumi. 
Hasil studi yang dilakukan oleh Triyatno, (2018) juga memberikan hasil yang sama dimana pemakaian jaringan gas bumi pada masyarakat Bontang, Kalimantan Timur lebih menguntungkan dibandingkan dengan pemakaian LPG. Namun dengan 118 responden dan tidak fokus pada satu jenis pengguna, studi yang dilakukan Triyatno, (Triyanto, 2018) kurang mewakili keadaan masyarakat Bontang khususnya bagi pengguna LPG rumah tangga.

Dari perhitungan kebutuhan gas bumi rata-rata setiap rumah/responden dapat dihitung kebutuhan gas untuk rumah tangga di Kabupaten Bojonegoro (415,733 rumah tangga pada tahun 2019) yaitu 6.48 mmscfd, jumlah gas bumi tersebut adalah sekitar $3.38 \%$ dari total produksi gas (192 mmscfd) yang dihasilkan dari perut bumi Bojonegoro (Amelia, 2019). Dengan predikat sebagai salah satu kabupaten penghasil minyak dan gas terbesar di Indonesia sudah seharusnya warga Bojonegoro ikut menikmati gas bumi yang dihasilkan dari wilayah mereka.

\section{SIMPULAN}

Gas bumi yang akan disalurkan ke rumah tangga melalui jaringan pipa gas di kabupaten Bojonegoro akan menjadi bahan bakar pengganti LPG selama harganya lebih murah dari LPG dan ketersediaannya melimpah. Jumlah pemakai LPG $3 \mathrm{~kg}$ adalah 93\%, LPG $12 \mathrm{~kg} 6 \%$ dan LPG $5.5 \mathrm{~kg} 1 \%$ dari total jumlah responden yang disurvei sehingga berdasarkan jumlah total pemakaian LPG, kebutuhan gas bumi per responden adalah $12.39 \mathrm{~m}^{3} /$ bulan. Penghematan biaya per tabung yang diperoleh dari pemakaian gas bumi ini sebesar Rp 878,- (LPG 3 kg), Rp 71,277,- (LPG $5.5 \mathrm{~kg}$ ) dan Rp 76,913,- (LPG $12 \mathrm{~kg}$ ). Total kebutuhan gas untuk pemakaian jargas 4,000 rumah tangga responden di Kabupaten Bojonegoro adalah sebesar $0.062 \mathrm{mmscfd}$ dan untuk seluruh rumah tangga di Kabupaten Bojonegoro adalah sebesar 6.48 mmscfd. Jumlah ini cukup kecil dibandingkan produksi gas dari perut bumi Bojonegoro yang mencapai 192 mmscfd sehingga jaringan gas bumi layak menggantikan LPG untuk memenuhi kebutuhan sehari-hari rumah tangga di kabupaten Bojonegoro.

\section{UCAPAN TERIMA KASIH}

Terima kasih kepada PT. Pertamina Gas yang telah memberikan data-data dalam studi ini melalui proyek Pembaharuan Front
End Engineering Design (FEED) dan Detailed Engineering Design For Construction (DEDC) Pembangunan Jaringan Gas Bumi Untuk Rumah Tangga (Jargas) di Kabupaten Bojonegoro Tahun 2018.

\section{DAFTAR PUSTAKA}

Amelia, A. R. (2019) Pertamina Mulai Bangun Fasilitas Gas Di Jambaran Tiung Biru. Available

At: Https://Katadata.Co.Id/Berita/2019/01 /04/Pertamina-Mulai-Bangun-FasilitasGas-Di-Jambaran-Tiung-Biru (Accessed: 7 November 2019).

Cahyono, E. (2019) Bojonegoro, Sesuai Pergub HET LPG 3 Kilo Rp 16 Ribu, TRANSBOJONEGORO. Available At: Http: / /Www.Transbojonegoro.Com/20 19/07/Bojonegoro-Sesuai-Pergub-HetLpg-3-Kilo-Rp-16-Ribu/ (Accessed: 24 September 2019).

Copiello, S. (2018) 'Expansion Of The Italian Natural Gas Network To The Sardinia Island: Economic Assessment', Journal Of Natural Gas Science And Engineering, 54, Pp. 297-308.

Kabupaten Bojonegoro Dalam Angka. Seksi Inte (2019). Bojonegoro: BPS Kabupaten Bojonegoro. Available At: Https://Bojonegorokab.Bps.Go.Id/Publi cation/Download.

KESDM (2016) Pembangunan Jaringan Gas Bumi Untuk Rumah Tangga. Jakarta: KESDM - Direktorat Jendral Minyak Dan Gas Bumi. Available At: Www.Migas.Esdm.Go.Id.

KESDM (2019) Laporan Tahunan CAPAIAN PEMBANGUNAN 2018. Jakarta. Available At:

Https://Migas.Esdm.Go.Id/Uploads/Upl oads/Files/Laporan-Tahunan/LaptahMigas-2018---FINAL.Pdf.

Lestari, L. And Aliasuddin (2016) 'Willingness To Pay Masyarakat Terhadap Pembangunan Jaringan Gas Bumi Untuk Rumah Tangga Di Kota Lhokseumawe', Jurnal Ilmiah Mahasiswa (JIM) Ekonomi Pembangunan Fakultas Ekonomi Dan Bisnis Unsyiah, 1(2), Pp. 409-419.

Liu, G. Et Al. (2018) 'Natural Gas Consumption Of Urban Households In China And Corresponding Influencing Factors', Energy Policy. Elsevier, 122, Pp. 17-26.

Marques, A. C. And Silva, P. (2019) 'Is There A Resource Curse Phenomenon For Natural Gas? Eviden From Countries 
With Abundant Natural Gas', Resources Policy, 63.

Migas Bojonegoro (2019). Available At: Http:/ /Www. Bojonegorokab.Go.Id/Men $\mathrm{u} /$ Index/Migas (Accessed: 24 September 2019).

Neraca Gas Bumi Indonesia 2018-2027 (2018). Jakarta: Kesdm - Direktorat Jendral Minyak Dan Gas Bumi.

No-Authors (2016) Harga Isi Gas Blue Gaz Tetap Dan Gratis Tukar Tabung Berpengaman Ganda Di Sepanjang Tahun 2016, Blue Gaz. Available At: Http:/ /Www.Bluegaz.Co.Id/I18-

1/Harga-Isi-Gas-Blue-Gaz-Tetap-DanGratis-Tukar-Tabung-BerpengamanGanda-Di-Sepanjang-Tahun-2016.Html (Accessed: 27 September 2019).

No-Authors (2017) Harga Elpiji $12 \mathrm{Kg}$ Rumah Tangga Ditingkat Agen Tmt 8 November 2017, Pertamina. Available At: Https://Www.Pertamina.Com/Id/Viewa rchive/Announcement/Harga-Elpiji-12Kg-Rumah-Tangga-Ditingkat-Agen-Tmt8-November-2017 (Accessed: 27 September 2019).

Peraturan Presiden Republik Indonesia Nomor 6 Tahun 2019 Tentang Penyediaan Dan Pendistribusian Gas Bumi Melalui Jaringan Transmisi Dan Distribusi Gas Bumi Untuk Rumah Tangga Dan Pelanggan Kecil (2019). Indonesia.

Pratiwi, I. And Yolanda, F. (2019) Harga Gas Rumah Tangga Dipatok Rp 4,250 Dan Rp 6,250, Ekonomi. Available At: Https: / /Www.Republika.Co.Id/Berita/E konomi/Migas/Pnw202370/Harga-Gas-

Rumah-Tangga-Dipatok-Rp-4250-DanRp-6250 (Accessed: 26 November 2019).

Pt. Pertamina Training \& Consulting (2018) Laporan Akhir Pembaharuan Front End Engineering Design (Feed) Dan Detail Engineering Design For Construction (Dedc) Pembangunan Jaringan Gas Bumi Untuk Rumah Tangga (Jargas) Di Kabupaten Bojonegoro. Jakarta.

Syukur, M. H. (2011) 'Penggunaan Liquified Petroleum Gases (Lpg): Upaya Mengurangi Kecelakaan Akibat Lpg', Publikasi Karya Ilmiah Pusdiklat Migas, $01(2)$. Available

At: Http:/ / Ejurnal.Ppsdmmigas.Esdm.Go.Id /Sp/Index.Php/Swarapatra/Issue/View/ 6.

Triyatno, J. (2018) 'Perbandingan Penggunaan Gas Alam Terhadap Lpg Dalam Memenuhi Kebutuhan Rumah
Tangga Di Bontang', Al Ulum Sains Dan Teknologi, 4(1), Pp. 14-20.

Valentino, N. (2012) Pengembangan Jaringan Pipa Distribusi Gas Bumi Untuk Rumah Tangga Di Kota Depok. Universitas Indonesia.

Wiguna, D. P., Koestoer, R. H. And Indra, T. L. (2015) 'Model Spasial Potensi Pengembangan Pengguna Bahan Bakar Gas Melalui Jaringan Pipa Gas Di Kabupaten Bekasi', Jurnal Ilmiah Geomatika, 21(2), Pp. 81-90.

Yulianita, E. (2019) Persepsi Masyarakat Terhadap Pembangunan Jaringan Gas Rumah Tangga (Studi Pada Kelurahan Kelapa Tiga Kecamatan Tanjung Karang Pusat Kota Bandar Lampung). Universitas Lampung. 